S.Shaimardan ${ }^{1}$, S.Shalgynbaeva
${ }^{2}$ Kazakh Ablai Khan University of International Relations and World Languages, Almaty, Kazakhstan
${ }^{1}$ L.N. Gumilyov Eurasian National University, Astana, Kazakhstan;

(E-mail: salta_sinar@mail.ru)

\title{
Hardy-type inequalities for matrix operators
}

We establish necessary and sufficient conditions the validity of the discrete Hardy-type inequality

$$
\left(\sum_{i=1}^{\infty}\left(\sum_{j=1}^{\infty} a_{i, j} f_{j}\right)^{q} u_{i}^{q}\right)^{\frac{1}{q}} \leq\left(\sum_{i=1}^{\infty} f_{i}^{p} v_{i}^{p}\right)^{\frac{1}{p}}, f=\left\{f_{i}\right\}_{i=1}^{\infty} \geq 0
$$

with $0<p \leq q<\infty$ and $0<p \leq 1$, where the matrices $\left(a_{i, j}\right)$ is an arbitrary matrix and the entries of the matrix $\left(a_{i, j}\right) \geq 0$ such that $a_{i, j}$ is non-increasing in the second index. Also some further results are pointed out on the cone of monotone sequences. Moreover, we give that the applications of the main results for the non-negative and triangular matrices $\left(a_{i, j} \geq 0\right.$ for $1 \leq j \leq i$ and $a_{i, j}=0$ for $\left.i<j\right)$.

Keywords: inequality, weighted sequences, matrix operators, integral.

\section{Introduction and preliminaries}

Let $0<p, q<\infty$. Let $\omega_{i}=\left\{\omega_{i, k}\right\}_{k=1}^{\infty}$ and $u=\left\{u_{i}\right\}_{i=1}^{\infty}$ be are non-negative real number sequences and $v=\left\{v_{i}\right\}_{i=1}^{\infty}$ be a positive real number sequence. $f=\left\{f_{i}\right\}_{i=1}^{\infty}$ is a non-negative sequence.

We consider the following inequalities:

$$
\left(\sum_{i=1}^{\infty}(\mathcal{A} f)_{i}^{q} u_{i}^{q}\right)^{\frac{1}{q}} \leq C\left(\sum_{i=1}^{\infty} f_{i}^{p} v_{i}^{p}\right)^{\frac{1}{p}}, \quad \forall f \geq 0,
$$

and

$$
\left(\sum_{j=1}^{\infty}\left(\mathcal{A}^{*} f\right)_{j}^{q} u_{j}^{q}\right)^{\frac{1}{q}} \leq C^{*}\left(\sum_{i=1}^{\infty} f_{i}^{p} v_{i}^{p}\right)^{\frac{1}{p}}, \quad \forall f \geq 0
$$

for the operators in the following form:

$$
\begin{aligned}
(\mathcal{A} f)_{i}: & =\sum_{j=1}^{\infty} a_{i, j} f_{j}, \quad i \geq 1 ; \\
\left(\mathcal{A}^{*} f\right)_{j}: & =\sum_{i=1}^{\infty} a_{i, j} f_{i}, \quad j \geq 1,
\end{aligned}
$$

respectively, where $C$ and $C^{*}$ - are positive finite constants independent of $f$ and $\left(a_{i, j}\right)$ is an arbitrary nonnegative matrix.

The main aim of this paper is to investigate that the problems necessary and sufficient conditions the validity of inequalities (1) and (2) with the case $0<p \leq q<\infty, 0<p<1$ and under weaker conditions on the matrices $\left(a_{i, j}\right)$ in operators defined by (3) and (4) for all sequences $f \geq 0$ (see theorems 2.1-2.2). Moreover, we study these problems on the cone of monotone sequences (see theorems 2.3-2.6). Finally, we will get the applications of the main results.

Notation. The symbol $M \ll K$ means that there exists $\alpha>0$ such that $M \leq \alpha K$, where $\alpha$ is a constant which may depend only on parameters such as $p, q$, $r$. If $M \ll K \ll M$, then we write $M \approx K$. 
We also need the following well-known result (see [1]):

Lemma A. [1]. Let $\gamma>0$. Then

$$
\left(\sum_{k=1}^{j} \beta_{k}\right)^{\gamma} \approx \sum_{k=1}^{j} \beta_{k}\left(\sum_{i=1}^{k} \beta_{i}\right)^{\gamma-1}, \quad \forall j \in \mathbb{N},
$$

for all sequences $\left\{\beta_{k}\right\}_{k=1}^{\infty}$ of positive real numbers and

$$
\left(\sum_{k=j}^{N} \beta_{k}\right)^{\gamma} \approx \sum_{k=j}^{N} \beta_{k}\left(\sum_{i=k}^{N} \beta_{i}\right)^{\gamma-1},
$$

for all $j, k \in\{1,2, \ldots, N\}, N \in \mathbb{N} \cup\{\infty\}$ and for all sequences $\left\{\beta_{k}\right\}_{k=1}^{\infty}$ of positive real numbers such that $\sum_{k=1}^{\infty} \beta_{k}<\infty$.

The main results

2. On nonnegative sequences

Our main results read as follows.

Theorem 2.1. Let $0<p \leq q<\infty$ and $0<p \leq 1$. Let the entries of the matrix $\left(a_{i, j}\right) \geq 0$ such that $a_{i, j}$ is non-increasing in the second index. Then the inequality (1) holds if and only if

$$
\mathcal{B}=\sup _{j \geq 1}\left(\sum_{i=1}^{\infty} a_{i, j}^{q} u_{i}^{q}\right)^{\frac{1}{q}} v_{j}^{-1}<\infty,
$$

holds. Moreover, $\mathcal{B} \approx C$, where $C$ is the best constant in (1).

Theorem 2.2. Let $0<p \leq q<\infty$ and $0<p \leq 1$. Let the entries of the matrix $\left(a_{i, j}\right) \geq 0$ such that $a_{i, j}$ is non-decreasing in the first index. Then the inequality (2) holds if and only if

$$
\mathcal{B}^{*}=\sup _{i \geq 1}\left(\sum_{j=1}^{\infty} a_{i, j}^{q} u_{j}^{q}\right)^{\frac{1}{q}} v_{i}^{-1}<\infty,
$$

holds. Moreover, $\mathcal{B}^{*} \approx C^{*}$, where $C^{*}$ is the best constant in (2).

Proof of Theorem 2.1. Necessity. Let the inequality (1) holds. Let us show that $\mathcal{B}<\infty$. For $1 \leq j \leq k \leq i$, we assume that

$$
\widetilde{f}=\left\{\widetilde{f}_{j}\right\}_{j=1}^{\infty}: \quad \widetilde{f}_{j}= \begin{cases}1, & j=k \\ 0, & j \neq k\end{cases}
$$

By substituting $\widetilde{f}$ into the inequality (1) we get that

$$
C v_{k} \geq\left(\sum_{i=1}^{\infty} a_{i, k}^{q} u_{i}^{q}\right)^{\frac{1}{q}} .
$$

Therefore

$$
\mathcal{B} \ll C .
$$

The proof of necessity is complete.

Sufficiency. Let $\mathcal{B}<\infty$. Now, we prove the inequality (1) holds. Let $f=\left\{f_{i}\right\}_{i=1}^{\infty}$ be a non-negative sequence. Then for $1 \leq n<\infty$ we assume that $f^{\varepsilon}=\left\{f_{i}^{\varepsilon}\right\}_{i=1}^{\infty}$ :

$$
f_{j}^{\varepsilon}=\left\{\begin{array}{ll}
f_{i}+\varepsilon, & 1 \leq j \leq n, \\
0, & j>n,
\end{array} a_{i, j}^{\delta}= \begin{cases}a_{i, j}+\delta, & 1 \leq j \leq n, \\
a_{i, j}, & j>n\end{cases}\right.
$$

where $\delta, \varepsilon>0$. 
Since $a_{i, k} \geq a_{i, j}, 1 \leq k \leq j$, then using the (5) we find that

$$
\begin{aligned}
\sum_{j=1}^{n} a_{i, j} f_{j}^{\varepsilon} \leq & \sum_{j=1}^{n} a_{i, j}^{\delta} f_{j}^{\varepsilon} \approx\left(\sum_{j=1}^{n} a_{i, j}^{\delta} f_{j}^{\varepsilon}\left(\sum_{k=1}^{j} a_{i, k}^{\delta} f_{k}^{\varepsilon}\right)^{p-1}\right)^{\frac{1}{p}} \leq \\
& \leq\left(\sum_{j=1}^{n}\left(a_{i, j}^{\delta}\right)^{p} f_{j}^{\varepsilon}\left(\sum_{k=1}^{j} f_{k}^{\varepsilon}\right)^{p-1}\right)^{\frac{1}{p}} .
\end{aligned}
$$

From (9) its follows that

$$
\begin{gathered}
I_{n}:=\left(\sum_{i=1}^{n}\left(\sum_{j=1}^{n} a_{i, j} f_{j}\right)^{q} u_{i}^{q}\right)^{\frac{1}{q}} \leq \\
\leq\left(\sum_{i=1}^{n}\left(\sum_{j=1}^{n} a_{i, j}^{\delta} f_{j}^{\varepsilon}\right)^{q} u_{i}^{q}\right)^{\frac{1}{q}} \leq \\
\leq\left(\sum_{i=1}^{n}\left(\sum_{j=1}^{n}\left(a_{i, j}^{\delta}\right)^{p} f_{j}^{\varepsilon}\left(\sum_{k=1}^{j} f_{k}^{\varepsilon}\right)^{p-1}\right)^{\frac{q}{p}} u_{i}^{q}\right)^{\frac{1}{q}} .
\end{gathered}
$$

Now, we apply Minkowski's inequality for $\frac{q}{p} \geq 1$ and we find that

$$
I_{n} \leq\left(\sum_{j=1}^{n} f_{j}^{\varepsilon}\left(\sum_{k=1}^{j} f_{k}^{\varepsilon}\right)^{p-1}\left(\sum_{i=1}^{n}\left(a_{i, j}^{\delta}\right)^{q} u_{i}^{q}\right)^{\frac{p}{q}}\right)^{\frac{1}{p}} .
$$

From $\lim _{\delta \rightarrow 0} a_{i, j}^{\delta}=a_{i, j}$ it follows that

$$
\begin{gathered}
I_{n} \leq\left(\sum_{j=1}^{n} f_{j}^{\varepsilon}\left(\sum_{k=1}^{j} f_{k}^{\varepsilon}\right)^{p-1}\left(\sum_{i=1}^{n}\left(a_{i, j}\right)^{q} u_{i}^{q}\right)^{\frac{p}{q}}\right)^{\frac{1}{p}} \leq \\
\leq \mathcal{B}\left(\sum_{j=1}^{n} f_{j}^{\varepsilon}\left(\sum_{k=1}^{j} f_{k}^{\varepsilon}\right)^{p-1} v_{j}^{p}\right)^{\frac{1}{p}} .
\end{gathered}
$$

Since $\left(f_{j}^{\varepsilon}\right)^{p-1} \geq\left(\sum_{k=1}^{j} f_{k}^{\varepsilon}\right)^{p-1}$ for $0<p \leq 1$, we drive that

$$
I_{n} \leq \mathcal{B}\left(\sum_{j=1}^{n}\left(f_{j}^{\varepsilon}\right)^{p} v_{j}^{p}\right)^{\frac{1}{p}}
$$

where $f_{j}^{\varepsilon} \rightarrow f_{j}$ as $\varepsilon \rightarrow 0$. Consequently,

$$
I_{n} \leq \mathcal{B}\left(\sum_{j=1}^{n} f_{j}^{p} v_{j}^{p}\right)^{\frac{1}{p}}
$$

Since $\forall n \in N$, we have that

$$
\left(\sum_{i=1}^{\infty}\left(\sum_{j=1}^{\infty} a_{i, j} f_{j}\right)^{q} u_{i}^{q}\right)^{\frac{1}{q}} \leq \mathcal{B}\left(\sum_{j=1}^{\infty} f_{j}^{p} v_{i}^{p}\right)^{\frac{1}{p}}
$$


i.e.

$$
C \ll \mathcal{B} .
$$

Thus, by combining (8) and (10) its follows that $\mathcal{B} \approx C$. The proof is complete. details.

The proof of the Theorem 2.2 is completely analogous to the proof of Theorem 2.1, so we leave out the

\subsection{On monotone sequences}

Assume that

$$
\begin{aligned}
& B=\sup _{k \geq 1}\left(\sum_{i=1}^{\infty}\left(\sum_{j=1}^{k} a_{i, j}\right)^{q} u_{i}^{q}\right)^{\frac{1}{q}}\left(\sum_{m=1}^{k} v_{m}^{p}\right)^{-\frac{1}{p}} ; \\
& B^{*}=\sup _{k \geq 1}\left(\sum_{j=1}^{\infty}\left(\sum_{i=k}^{\infty} a_{i, j}\right)^{q} u_{j}^{q}\right)^{\frac{1}{q}}\left(\sum_{m=k}^{\infty} v_{m}^{p}\right)^{-\frac{1}{p}} ; \\
& A:=\sup _{k \geq 1}\left(\sum_{i=1}^{k} u_{i}^{q}\right)^{\frac{1}{q}}\left(\sum_{j=1}^{\infty}\left(\sum_{j=1}^{k} a_{i, j}\right)^{p} v_{j}^{p}\right)^{-\frac{1}{p}} ; \\
& A^{*}:=\sup _{k \geq 1}\left(\sum_{i=k}^{\infty} u_{i}^{q}\right)^{\frac{1}{q}}\left(\sum_{j=1}^{\infty}\left(\sum_{i=k}^{\infty} a_{i, j}\right)^{p} v_{j}^{p}\right)^{-\frac{1}{p}}
\end{aligned}
$$

Our main result for the operators defined by (3) and (4) on the cone of monotone sequences reads as follows:

Theorem 2.3. Let $0<p \leq q<\infty$ and $0<p \leq 1$. Then the inequality (1) on the cone of non-negative and non-increasing sequences $f=\left\{f_{k}\right\}_{k=1}^{\infty}$ holds if and only if $B<\infty$ holds. Moreover, $B \approx C$, where $C$ is the best constant in (1).

Theorem 2.4. Let $0<p \leq q<\infty$ and $0<p \leq 1$. Then the inequality (2) on the cone of non-negative and non-decreasing sequences $f=\left\{f_{k}\right\}_{k=1}^{\infty}$ holds if and only if $B^{*}<\infty$ holds. Moreover, $B^{*} \approx C^{*}$, where $C^{*}$ is the best constant in (2).

Theorem 2.5. Let $1<p \leq q<\infty$. Then the inequality

$$
\left(\sum_{i=1}^{\infty} f_{i}^{q} u_{i}^{q}\right)^{\frac{1}{q}} \leq C\left(\sum_{i=1}^{\infty}(\mathcal{A} f)_{i}^{p} v_{i}^{p}\right)^{\frac{1}{p}},
$$

on the cone of non-negative and non-increasing sequences $f=\left\{f_{k}\right\}_{k=1}^{\infty}$ holds if and only if $A<\infty$ holds. Moreover, $A \approx C$, where $C$ is the best constant in (11).

Theorem 2.6. Let $1<p \leq q<\infty$. Then the inequality

$$
\left(\sum_{i=1}^{\infty} f_{i}^{q} u_{i}^{q}\right)^{\frac{1}{q}} \leq C^{*}\left(\sum_{j=1}^{\infty}\left(\mathcal{A}^{*} f\right)_{j}^{p} u_{j}^{p}\right)^{\frac{1}{p}}
$$

on the cone of non-negative and non-decreasing sequences $f=\left\{f_{k}\right\}_{k=1}^{\infty}$ holds if and only if $A^{*}<\infty$ holds. Moreover, $A^{*} \approx C^{*}$, where $C^{*}$ is the best constant in (12).

The proof of the Theorem 2.4 and 2.6 are completely analogous to the proof of Theorem 2.3 and 2.5 respectively, so we will only prove Theorems 2.3 and 2.5 .

Proof of Theorem 2.3. Necessity. Suppose that the inequality (1) holds with the best constant $C>0$. We take a test sequence $\hat{f}_{k}=\left\{\hat{f}_{j}\right\}_{j=1}^{\infty}$ such that

$$
\hat{f}_{j}= \begin{cases}1, & 1 \leq j \leq k \\ 0, & j>k\end{cases}
$$

for $1 \leq k<\infty$. 
Substituting the test sequence $\hat{f}_{k}$ in the inequality (1) we obtain that

$$
C\left(\sum_{i=1}^{k} v_{i}^{p}\right)^{\frac{1}{p}} \geq\left(\sum_{i=1}^{\infty}\left(\sum_{j=1}^{k} a_{i, j}\right)^{q} u_{i}^{q}\right)^{\frac{1}{q}}
$$

i.e.

$$
B \ll C \text {. }
$$

The proof of necessity is complete.

Sufficiency. Let the inequality (1) holds. We will show that $B<\infty$. We known that for all non-negative and non-increasing sequence $f=\left\{f_{j}\right\}_{j=1}^{\infty}$ write in the form:

$$
f_{j}=\tilde{f}_{j}+c, \quad c \geq 0
$$

where $\tilde{f}_{j} \geq \tilde{f}_{j+1} \geq 0$, for $j \geq 1$ and $\lim _{j \rightarrow \infty} \tilde{f}_{j}=0$.

We consider two cases separately: $\sum_{k=1}^{\infty} v_{k}^{p}=\infty$ and $\sum_{k=1}^{\infty} v_{k}^{p}<\infty$.

Let $\sum_{k=1}^{\infty} v_{k}^{p}=\infty$. Then $c=0$ and $f_{j}=\tilde{f}_{j}$ for $j \geq 1$.

We suppose that $\left\{g_{j}\right\}_{j=0}^{\infty}: g_{j}>0, g_{j}>g_{j+1}, \lim _{j \rightarrow \infty} g_{j}=0$ and $f_{j}^{\varepsilon}=\tilde{f}_{j}+\varepsilon g_{j}$. Then $f_{j}^{\varepsilon}>f_{j+1}^{\varepsilon}, \lim _{j \rightarrow \infty} f_{j}^{\varepsilon}=0$. Let $a_{j}=\Delta \tilde{f}_{j}=\tilde{f}_{j}-\tilde{f}_{j+1} \geq 0, b_{j}=\Delta g_{j}>0, c_{j}^{\varepsilon}=\Delta f_{j}^{\varepsilon}>0$. Then $c_{j}^{\varepsilon}=a_{j}+\varepsilon b_{j}$ and $f_{j}^{\varepsilon}=\sum_{k=j}^{\infty} c_{k}^{\varepsilon}$. From (6) its follows that

$$
f_{i}^{\varepsilon} \approx\left(\sum_{k=j}^{\infty} c_{k}^{\varepsilon}\left(\sum_{m=k}^{\infty} c_{m}^{\varepsilon}\right)^{p-1}\right)^{\frac{1}{p}}
$$

By using (14) and apply Minkowski's inequality for $\frac{1}{p} \geq 1$, we find that

$$
\begin{gathered}
\sum_{j=1}^{\infty} a_{i, j} f_{j}^{\varepsilon} \approx \sum_{j=1}^{\infty} a_{i, j}\left(\sum_{k=j}^{\infty} c_{k}^{\varepsilon}\left(\sum_{m=k}^{\infty} c_{m}^{\varepsilon}\right)^{p-1}\right)^{\frac{1}{p}} \leq \\
\leq\left(\sum_{k=1}^{\infty} c_{k}^{\varepsilon}\left(\sum_{m=k}^{\infty} c_{m}^{\varepsilon}\right)^{p-1}\left(\sum_{j=1}^{k} a_{i, j}\right)^{p}\right)^{\frac{1}{p}}
\end{gathered}
$$

and

$$
\begin{gathered}
I\left(f^{\varepsilon}\right):=\left(\sum_{i=1}^{\infty}\left(A f^{\varepsilon}\right)_{i}^{q} u_{i}^{q}\right)^{\frac{1}{q}} \leq \\
\leq\left(\sum_{i=1}^{\infty}\left(\sum_{k=1}^{\infty} c_{k}^{\varepsilon}\left(\sum_{m=k}^{\infty} c_{m}^{\varepsilon}\right)^{p-1}\left(\sum_{j=1}^{k} a_{i, j}\right)^{p}\right)^{\frac{q}{p}} u_{i}^{q}\right)^{\frac{1}{q}} .
\end{gathered}
$$

Next, apply Minkowski's inequality for $\frac{q}{p} \geq 1$ and using (6), we get that

$$
\begin{gathered}
I(\tilde{f})<I\left(f^{\varepsilon}\right) \leq \\
\leq\left(\sum_{k=1}^{\infty} c_{k}^{\varepsilon}\left(\sum_{m=k}^{\infty} c_{m}^{\varepsilon}\right)^{p-1}\left(\sum_{i=1}^{\infty}\left(\sum_{j=1}^{k} a_{i, j}\right)^{q} u_{i}^{q}\right)^{\frac{p}{q}}\right)^{\frac{1}{p}} \leq
\end{gathered}
$$




$$
\begin{gathered}
\leq B\left(\sum_{k=1}^{\infty} c_{k}^{\varepsilon}\left(\sum_{m=k}^{\infty} c_{m}^{\varepsilon}\right)^{p-1} \sum_{i=1}^{k} v_{i}^{p}\right)^{\frac{1}{p}}= \\
=B\left(\sum_{i=1}^{\infty} v_{i}^{p} \sum_{k=i}^{\infty} c_{k}^{\varepsilon}\left(\sum_{m=k}^{\infty} c_{m}^{\varepsilon}\right)^{p-1}\right)^{\frac{1}{p}} \approx \\
\approx B\left(\sum_{i=1}^{\infty} v_{i}^{p}\left(f_{i}^{\varepsilon}\right)^{p}\right)^{\frac{1}{p}} .
\end{gathered}
$$

Since $I(f)=I(\tilde{f})$ and $\lim _{\varepsilon \rightarrow 0} f_{i}^{\varepsilon}=\lim _{\varepsilon \rightarrow 0}\left[\tilde{f}_{j}+\varepsilon g_{j}\right]=f$ we have that

$$
I(f)<B\left(\sum_{i=1}^{\infty} v_{i}^{p}\left(f_{i}\right)^{p}\right)^{\frac{1}{p}} .
$$

Therefore,

$$
C \ll B
$$

Let $\sum_{k=1}^{\infty} v_{k}^{p}<\infty$. Then

$$
I(f)=\left(\sum_{i=1}^{\infty}(A f)_{i}^{q} u_{i}^{q}\right)^{\frac{1}{q}} \approx I(\tilde{f})+c\left(\sum_{i=1}^{\infty}\left(\sum_{j=1}^{\infty} a_{i, j}\right)^{q} u_{i}^{q}\right)^{\frac{1}{q}} .
$$

Since $\left(\sum_{i=1}^{\infty}\left(\sum_{j=1}^{\infty} a_{i, j}\right)^{q} u_{i}^{q}\right)^{\frac{1}{q}}\left(\sum_{i=1}^{\infty} v_{i}^{p}\right)^{-\frac{1}{p}} \leq B$, then from (15) we obtain that

$$
\begin{gathered}
I(f) \leq B\left(\sum_{i=1}^{\infty} v_{i}^{p} \tilde{f}_{j}^{p}\right)^{\frac{1}{p}}+B\left(\sum_{i=1}^{\infty} c^{p} v_{i}^{p}\right)^{\frac{1}{p}} \approx \\
\approx B\left(\sum_{i=1}^{\infty} v_{i}^{p}\left(\tilde{f}_{j}+c\right)^{p}\right)^{\frac{1}{p}}= \\
=B\left(\sum_{i=1}^{\infty} v_{i}^{p} f_{j}^{p}\right)^{\frac{1}{p}} .
\end{gathered}
$$

Therefore,

$$
C \ll B,
$$

and (1) holds. According to (14) and (18), we have that $B \approx C$, where $C$ is the best constant for which (1) holds. The proof is complete.

Proof of Theorem 2.5. The Necessity part in the same way as to proof of Theorem 2.3. Therefore,

$$
A \ll C .
$$

To prove sufficiency we proceed as follows. We assume that $\sum_{k=1}^{\infty} v_{k}^{p}=\infty$. By using (14) and apply Minkowski's inequality for $\frac{q}{p} \geq 1$, we find that

$$
J\left(f^{\varepsilon}\right):=\left(\sum_{i=1}^{\infty}\left(f_{i}^{\varepsilon}\right)^{q} u_{i}^{q}\right)^{\frac{p}{q}} \approx
$$




$$
\begin{gathered}
\approx\left(\sum_{i=1}^{\infty}\left(\sum_{m=i}^{\infty} c_{m}^{\varepsilon}\left(\sum_{k=m}^{\infty} c_{k}^{\varepsilon}\right)^{p-1}\right)^{\frac{q}{p}} u_{i}^{q}\right)^{\frac{p}{q}} \leq \\
\leq \sum_{m=1}^{\infty} c_{m}^{\varepsilon}\left(\sum_{k=m}^{\infty} c_{k}^{\varepsilon}\right)^{p-1}\left(\sum_{i=1}^{m} u_{i}^{q}\right)^{\frac{p}{q}} .
\end{gathered}
$$

By using

$$
\left(\sum_{i=1}^{m} u_{i}^{q}\right)^{\frac{p}{q}} \leq A^{p} \sum_{i=1}^{\infty}\left(\sum_{j=1}^{m} a_{i, j}\right)^{p} v_{i}^{p}
$$

and applying Minkowski's inequality for $p>1$ and (6) we have that

$$
\begin{gathered}
J(\tilde{f})<J\left(f^{\varepsilon}\right) \leq A^{p} \sum_{m=1}^{\infty} c_{m}^{\varepsilon}\left(\sum_{k=m}^{\infty} c_{k}^{\varepsilon}\right)^{p-1} \sum_{i=1}^{\infty}\left(\sum_{j=1}^{m} a_{i, j}\right)^{p} v_{i}^{p}= \\
=A^{p} \sum_{i=1}^{\infty}\left[\left(\sum_{m=1}^{\infty} c_{m}^{\varepsilon}\left(\sum_{k=m}^{\infty} c_{k}^{\varepsilon}\right)^{p-1}\left(\sum_{j=1}^{m} a_{i, j}\right)^{p}\right)^{\frac{1}{p}}\right]^{p} v_{i}^{p} \leq \\
\leq A^{p} \sum_{i=1}^{\infty}\left[\sum_{j=1}^{\infty} a_{i, j}\left(\sum_{m=j}^{\infty} c_{m}^{\varepsilon}\left(\sum_{k=m}^{\infty} c_{k}^{\varepsilon}\right)^{p-1}\right)^{\frac{1}{p}}\right]^{p} v_{i}^{p} \approx \\
\approx A^{p} \sum_{i=1}^{\infty}\left(\sum_{j=1}^{\infty} a_{i, j} f_{j}^{\varepsilon}\right)^{p} v_{i}^{p} .
\end{gathered}
$$

Since $J(f)=J(\tilde{f})$ and $\lim _{\varepsilon \rightarrow 0} f_{i}^{\varepsilon}=\lim _{\varepsilon \rightarrow 0}\left[\tilde{f}_{j}+\varepsilon g_{j}\right]=f$ we get that

$$
J(f)<A^{p} \sum_{i=1}^{\infty}\left(\sum_{j=1}^{\infty} a_{i, j} f_{j}\right)^{p} v_{i}^{p} .
$$

Therefore,

$$
C \ll A .
$$

Let $\sum_{k=1}^{\infty} v_{k}^{p}<\infty$. From (20) and (21) its follows that

$$
\begin{gathered}
J(f)=\left(\sum_{i=1}^{\infty}\left(c+g_{i}\right)^{\frac{q}{p}} u_{i}^{q}\right)^{\frac{p}{q}} \approx \\
\approx c^{p}\left(\sum_{i=1}^{\infty} u_{i}^{q}\right)^{\frac{p}{q}}+J(\tilde{f}) \leq \\
\leq A^{p} \sum_{i=1}^{\infty}\left(\sum_{j=1}^{\infty} a_{i, j} c\right)^{p} v_{i}^{p}+A^{p} \sum_{i=1}^{\infty}\left(\sum_{j=1}^{\infty} a_{i, j} \tilde{f}_{j}\right)^{p} v_{i}^{p} \approx \\
\approx A^{p} \sum_{i=1}^{\infty}\left(\sum_{j=1}^{\infty} a_{i, j}(c+\tilde{f})\right)^{p} v_{i}^{p}=
\end{gathered}
$$




$$
=A^{p} \sum_{i=1}^{\infty}\left(\sum_{j=1}^{\infty} a_{i, j} f_{j}\right)^{p} v_{i}^{p} .
$$

Therefore,

$$
A \ll C,
$$

and (11) holds. According to (19), (22) and (23), we have that $A \approx C$, where $C$ is the best constant for which (11) holds. The proof is complete.

\section{Applications}

The inequalities (1) and (2) have been investigated for the case $0<p, q<\infty$ with a triangular matrix $\left(a_{i, j} \geq 0\right.$ for $1 \leq j \leq i$ and $a_{i, j}=0$ for $i<j$ ) in [2-5] and the references given therein. However, these inequalities have not been studied for the case $0<p \leq q<\infty$ and $p \leq 1$. Only, in 1991 G. Bennett [3] studied the inequality (1) for the this case with the identity matrix. He proved that the inequality (1) holds if and only if

$$
\sup _{n \in N}\left(\sum_{k=n}^{\infty} u_{k}^{q}\right)^{\frac{1}{q}} v_{n}^{-p}<\infty
$$

holds for this case.

The continuous case it is known that the Hardy inequality is not holds for arbitrary non-negative measurable functions in $L_{p}$-spaces with $0<p<1$, but it is able to found the sharp constant in the Hardy-type inequality for non-negative monotone functions. Moreover, we can get the more informations about the direction in [7-11] and the references given therein. Therefore the investigation of the Hardy inequalities for matrix operators one of the big important question.

The corresponding results for the non-negative and triangular matrices $\left(a_{i, j} \geq 0\right.$ for $1 \leq j \leq i$ and $a_{i, j}=0$ for $i<j$ ) could have the following.

Corollary 3.1. Let $0<p \leq q<\infty$ and $0<p \leq 1$. Let the entries of the matrix $\left(a_{i, j}\right)$ such that $a_{i, j}$ is non-increasing in the second index. Then the inequality (1) holds if and only if

$$
\mathcal{B}_{1}=\sup _{j \geq 1}\left(\sum_{i=j}^{\infty}\left(a_{i, j}\right)^{q} u_{i}^{q}\right)^{\frac{1}{q}} v_{j}^{-1}<\infty
$$

holds. Moreover, $\mathcal{B}_{1} \approx C$, where $C$ is the best constant in (2).

Corollary 3.2. Let $0<p \leq q<\infty$ and $0<p \leq 1$. Let the entries of the matrix $\left(a_{i, j}\right)$ such that $a_{i, j}$ is non-decreasing in the first index. Then the inequality (2) holds if and only if

$$
\mathcal{B}^{*}{ }_{1}=\sup _{i \geq 1}\left(\sum_{j=1}^{i}\left(a_{i, j}\right)^{q} u_{j}^{q}\right)^{\frac{1}{q}} v_{i}^{-1}<\infty,
$$

holds. Moreover, $\mathcal{B}^{*}{ }_{1} \approx C^{*}$, where $C^{*}$ is the best constant in (2).

From Theorems 2.3-2.6 we obtain immediately the validity of the following statements:

Corollary 3.3. Let $0<p \leq q<\infty$ and $0<p \leq 1$. Then the inequality (1) on the cone of non-negative and non-increasing sequences $f=\left\{f_{k}\right\}_{k=1}^{\infty}$ holds if and only if $\widehat{B}_{1}<\infty$ holds. where

$$
\widehat{B}_{1}=\sup _{k \geq 1}\left(\sum_{i=j}^{\infty}\left(\sum_{j=1}^{k} a_{i, j}\right)^{q} u_{i}^{q}\right)^{\frac{1}{q}}\left(\sum_{m=1}^{k} v_{m}^{p}\right)^{-\frac{1}{p}}<\infty .
$$

Moreover, $\widehat{B} \approx C$, where $C$ is the best constant in (1). 
Corollary 3.4. Let $0<p \leq q<\infty$ and $0<p \leq 1$. Then the inequality (2) on the cone of non-negative and non-decreasing sequences $f=\left\{f_{k}\right\}_{k=1}^{\infty}$ holds if and only if $\widehat{B}_{1}^{*}<\infty$ holds. Where

$$
\widehat{B}_{1}^{*}=\sup _{k \geq 1}\left(\sum_{j=1}^{i}\left(\sum_{i=k}^{\infty} a_{i, j}\right)^{q} u_{j}^{q}\right)^{\frac{1}{q}}\left(\sum_{m=k}^{\infty} v_{m}^{p}\right)^{-\frac{1}{p}}<\infty .
$$

Moreover, $\widehat{B}^{*} \approx C^{*} . C^{*}$ is the best constant in (2).

Corollary 3.5. Let $1<p \leq q<\infty$. Then the inequality (11) on the cone of non-negative and non-increasing sequences $f=\left\{f_{k}\right\}_{k=1}^{\infty}$ holds if and only if $\mathcal{A}<\infty$ holds. Where

$$
\mathcal{A}:=\sup _{k \geq 1}\left(\sum_{i=1}^{k} u_{i}^{q}\right)^{\frac{1}{q}}\left(\sum_{j=1}^{i}\left(\sum_{i=1}^{k} a_{i, j}\right)^{p} v_{i}^{p}\right)^{-\frac{1}{p}} .
$$

Moreover, $\mathcal{A} \approx C . C$ is the best constant in (11).

Corollary 3.6. Let $1<p \leq q<\infty$. Then the inequality (12) on the cone of non-negative and non-decreasing sequences $f=\left\{f_{k}\right\}_{k=1}^{\infty}$ holds if and only if $\mathcal{A}^{*}<\infty$ holds. Where

$$
\mathcal{A}^{*}:=\sup _{k \geq 1}\left(\sum_{i=k}^{\infty} u_{i}^{q}\right)^{\frac{1}{q}}\left(\sum_{i=j}^{\infty}\left(\sum_{j=k}^{\infty} a_{i, j}\right)^{p} v_{i}^{p}\right)^{-\frac{1}{p}} .
$$

Moreover, $\mathcal{A}^{*} \approx C^{*} . C^{*}$ is the best constant in (12).

\section{Acknowledgments}

The authors wishes to thank Professor Ryskul Oinarov for several discussions and suggestions, which have improved the final version of this paper. This work was supported by Scientific Committee of Ministry of Education and Science of the Republic of Kazakhstan, grant no. 5495/GF4.

\section{References}

1 Oinarov, R., Okpoti, C.A. \& Persson, L.-E. (2007). Weighted inequalities of Hardy type for matrix operators: the case $q<p$, Math. Inequal. Appl., 10, 4, 843-861.

2 Oinarov, R. \& Taspaganbetova, Zh. (2012). Criteria of boundedness and compactness of a class of matrix operators. J. Inequal. Appl., 53, 1-18.

3 Oinarov, R., Persson, L-E. \& Temirkhanova, A.M. (2009). Weighted inequalities for a class of matrix operators: the case $p \leq q$, Math. Inequal. Appl., 12, 4, 891-903.

4 Taspaganbetova, Zh. (2013). Boundedness and Compactness of matrix operarors in weighted speces of sequences and applcations, $\mathrm{PhD}$ thesis, University of Padova, Italy, 118.

5 Temirkhanova, A.M. (2008). Weighted inequalities for a class of matrix operators: the case $1<q<p<\infty$. Eurasian Math. J., 2, 117-127.

6 Bennett, G. (1996). Some elementary inequalities. III, Quart. J. Math. Oxford Ser., 42, 166, 149-174.

7 Bandaliyev, R.A. (2010). On a two-weight criterion for Hardy type operator in the variable Lebesgue spaces with measures. Trans. of NAS of Azerbaijan, 304, 45-54.

8 Bandaliev, R.A. (2013). On Hardy type inequalities in weighted variable exponent spaces $L_{p(x), \omega}$ for $0<p(x)<1$. Eurasian Math. J., 4, 4, 5-16.

9 Mamedov, F.I. (2012). On Hardy type inequality in variable exponent Lebesgue space $L^{p(.)}(0 ; \ell)$ : Azerbaijan Jour. of Math., 2, 1, 96-106.

10 Mamedov, F.I. \& Mamedova, F.M. (2014). A necessary and suficient condition for Hardy's operator in $L^{p(.)}(0 ; \ell)$ : Math. Nachr., 287, 6, 666-676. 
11 Mamedov, F.I. (2012). On Hardy type inequality in variable exponent Lebesgue space $L^{p(.)}(0 ; \ell)$. Azerbaijan Jour. of Math., 2, 1, 194-203.

С.Шаймардан, С.Шалгинбаева

\section{Матрицалық операторлар үшін Харди типтес теңсіздіктер}

Мақалада Харди типтес дискретті теңсіздіктің қажетті және жеткілікті шарттары алынған

$$
\left(\sum_{i=1}^{\infty}\left(\sum_{j=1}^{\infty} a_{i, j} f_{j}\right)^{q} u_{i}^{q}\right)^{\frac{1}{q}} \leq\left(\sum_{i=1}^{\infty} f_{i}^{p} v_{i}^{p}\right)^{\frac{1}{p}}, f=\left\{f_{i}\right\}_{i=1}^{\infty} \geq 0,
$$

$0<p \leq q<\infty, 0<p \leq 1$, мұнда $\left(a_{i, j}\right)$ - еркін матрица, ал $\left(a_{i, j}\right) \geq 0$ және $a i, j$ - екінші индексте өсімсіз. Сондай-ақ жұмыста монотонды тізбектердің конусында кейбір нәтижелер көрсетілген. Сонымен қатар теріс емес және үшбұрышты матрицалар үшін негізгі қосымша нәтижелер берілген $\left(a_{i, j} \geq 0,1 \leq j \leq i\right.$ және $\left.a_{i, j}=0, i<j\right)$.

Kiлm сөздер: теңсіздік, тізбектер, матрицалық операторлар, интеграл.

\section{С.Шаймардан, С.Шалгинбаева}

\section{Неравенства типа Харди для матричных операторов}

В статье установлены необходимые и достаточные условия дискретного неравенства типа Харди

$$
\left(\sum_{i=1}^{\infty}\left(\sum_{j=1}^{\infty} a_{i, j} f_{j}\right)^{q} u_{i}^{q}\right)^{\frac{1}{q}} \leq\left(\sum_{i=1}^{\infty} f_{i}^{p} v_{i}^{p}\right)^{\frac{1}{p}}, f=\left\{f_{i}\right\}_{i=1}^{\infty} \geq 0
$$

$0<p \leq q<\infty, 0<p \leq 1$ где $\left(a_{i, j}\right)$ - произвольная матрица, а матрица $\left(a_{i, j}\right) \geq 0$ такая, что $a i, j$ не возрастает во втором индексе. Также указаны некоторые результаты на конусе монотонных последовательностей. Кроме того, даны приложения основных результатов для неотрицательных и треугольных матриц $\left(a_{i, j} \geq 0\right.$ и $1 \leq j \leq i$ и $a_{i, j}=0$ и $\left.i<j\right)$.

Ключевые слова: неравенство, взвешенные последовательности, матричные операторы, интеграл. 